\title{
A Study on the cooling effects of the park dispersions applied in PUD
}

\author{
Yi-Cheng Chiang ${ }^{1}$ and Hong-Yun Lin $^{2}$ \\ ${ }^{1}$ Assistant professor, Department of Landscape and Urban Design, Chaoyang University of Technology \\ ${ }^{2}$ Department of Landscape and Urban Design, Chaoyang University of Technology
}

\begin{abstract}
Urban heat-island effect causes the vicious cycle of city high temperature. The collocation of green park space can effectively cool down the heat of city. This research studies the cooling effects of the park dispersion by simulations of PUD projects. In this study, 3 different schemes were developed and simulated by CFD software. The results show that the more disperse the parks are, the lower the site temperatures.
\end{abstract}

Keyword. Urban thermal environment, Cold-island effect, Park scale, Park dispersion

\section{Introduction}

Most of Taiwan cities have developed according to urban plans and guidelines established in middle 19th century. Nowadays many of them come into a renewal period. Facing the climate of Urban Heat Island(UHI), climate responsive urban design requires comprehensive epistemology in different fields. Green park is an important element of urban composition. Many studies have found that the allocation of green park can effectively reduce the urban high temperature, which is called Cold Island Effect(CIE), and different scales of green park can produce different effects of CIE. It could be profound method for climate responsive urban design to suggest a green park configuration type with more effective CIE. This study investigates on the cooling effects of the park dispersion in order to find out the better dispersion types for climate responsive urban planning and design. The main issue is that in the limitation of green park area, how will various park dispersions impact the urban temperature?

\section{Literature Review}

The study reviews three kinds of papers, including Coldisland effects of parks, Thermal environments of different park allocations, Functions of different park scales, and Urban climate scale.

\subsection{Cold-island effects of parks}

The park green space has the function that mediates the climate, alleviates the hot environment in the city, this phenomenon is called the urban cool-island. Urban park green space compared to other urban areas have a lower temperature, the main reason for the park has a higher green cover area, the park's plants can produce shading and evaporation effect, can avoid direct sunlight surface and artificial facilities, endothermic caused by temperature rise, and through the plant body water distribution, increase the humidity in the environment away from heat.

\subsection{Thermal environments of different park allocations}

Many studies found that the park green space can effectively reduce urban high temperature, which in the park spatial distribution of environmental cooling effect of the study, C. T. Lin [1] ${ }^{1}$ found that the more dispersed park space distribution, the better the effect. In addition, the study on the effect of cooling in size and scale parks, $\mathrm{M}$. H Lee $[2]^{2}$ found that the range of cooling caused by dispersing several small parks is not significantly different from that of the whole big park. Wenqi Lina,b $[3]^{3}$ found that the cooling range of the park in different directions, the maximum cooling range reached $840 \mathrm{M}$, and the minimum cooling range of only $35 \mathrm{M}$. And regardless of the size of green space, the minimum temperature range is generally below $100 \mathrm{M}$, the median is generally below $200 \mathrm{M}$. This study refers to these three articles, further discussion of the decentralized model of the park, the scheme simulation for the cooling efficiency of this model.

\subsection{Functions of different park scales}


According to Taiwan CPAMI and the Taizhong government definition, the park green space function has the leisure, the landscape, the conservation and the Urban disaster prevention, provides the ecology, the society, the environmental benefit. The neighbourhood park in Taiwan's urban Park, 0.5-4 hectares, is the smallest unit of leisure and social gatherings $[4]^{4}$. Therefore, this study defines the neighbourhood Park below 4 hectares as a small-scale park, including Neighbourhood Park, Pocket Park. Compared with large-scale parks, small-scale parks are scattered in high-density cities. It has the characteristics of flexible location, small area and dispersed distribution, and it can in the city corners and has the most influence.

\subsection{Urban climate scale}

Ground environment will have an impact on atmospheric air layer, the climate of the ground layer is medium or small-scale climate, when the large-scale climate pattern performance is obvious, the microclimate scale performance is not obvious, conversely, the performance is not obvious, will be dominated by the small scale climate the lower atmosphere. (Fig. 1). In different scales, the degree of urban climate change and the impact factors are different, Masatoshi Yoshino [5] ${ }^{5}$. According to different regions, the climate is divided into different scales. (Table 1) Oke [6] ${ }^{6}$ urbanization and the influence of human activities will form local climate, according to different scales of the climate characteristics of the formation of the four regions: hints Bound Layer, hints canopy, hints Plume and Rural boundary Layer. (Fig. 2). The urban boundary layer hints Bound layer are mainly affected by the flow of heat energy from urban air pollutants and structures. The study explores the climate of the urban boundary layer, which is defined by the Man Mino microclimate, the horizontal range $10 \mathrm{~m}-10 \mathrm{~km}$, and the vertical range $10 \mathrm{~cm} \sim 1 \mathrm{~km}$. (Table 1 )

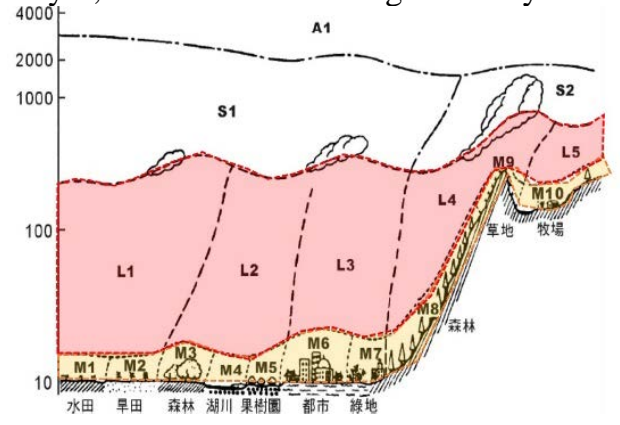

Figure 1. Climate scale diagram

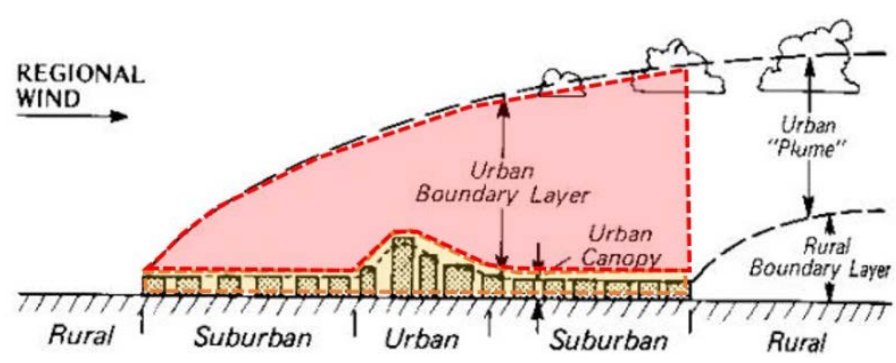

Figure 2. The urban plume

Table 1. Climate scale diagram

\begin{tabular}{|c|c|c|c|c|c|}
\hline Climate & Block number & $\begin{array}{c}\text { Horizontal range } \\
(\mathrm{m})\end{array}$ & $\begin{array}{c}\text { Vertical range } \\
(\mathbf{m})\end{array}$ & $\begin{array}{c}\text { Climate } \\
\text { phenomenon } \\
\end{array}$ & $\begin{array}{c}\text { Climate } \\
\text { phenomenon time }\end{array}$ \\
\hline Micro-climate & $\mathrm{M} 1 \sim \mathrm{M} 10$ & $10^{-2} \sim 10^{2}$ & $\begin{array}{c}10- \\
2 \sim 2 \times 100\end{array}$ & $\begin{array}{l}\text { Paddy } \\
\text { climate, } \\
\text { Greenhouse } \\
\text { climate }\end{array}$ & $\begin{array}{c}10-1 \sim 2 \times 101 \\
\text { sec. }\end{array}$ \\
\hline Micro-climate & L1 L5 & $10^{1} \sim 10^{4}$ & $10-1 \sim 103$ & $\begin{array}{l}\text { Frost Road, } \\
\text { Beveled } \\
\text { warm zone }\end{array}$ & 101 104 sec. \\
\hline Meso-climate & $\mathrm{S} 1 \sim \mathrm{S} 2$ & $10^{3} \sim 2 \times 10^{5}$ & $100 \sim 6 \times 108$ & $\begin{array}{l}\text { Urban } \\
\text { climate, } \\
\text { Basin } \\
\text { climate }\end{array}$ & 103 105 sec. \\
\hline Marco-climate & A1 & $(2 \sim 4) \times 10^{5} \sim 10^{7}$ & $100 \sim 2 \times 105$ & $\begin{array}{l}\text { Climate } \\
\text { zone, } \\
\text { Seasonal } \\
\text { wind band }\end{array}$ & 105 107 sec. \\
\hline
\end{tabular}

Based on the literature review, we know that the specific park distribution is beneficial to the cold island effect, but the literature in the past has been to simulate the existing environment, without taking into account the actual space 
structure in the physical environment and the configuration of the building, it is not known how to apply the space of urban development in the future, this study considers the applicability of the future, the paper will make further discussion on the effect of the dispersed mode of green park in urban planned development unit.

\section{Method}

By the CFD software Phoenics, the research method uses the scenarios simulation on PUD (Planned Unit Development) 12 of Taichung City. All the scenarios are assumed to be on the same district street networks and buildings codes based on the PUD original guidelines and masterplan. The impact of buildings and streets on microclimate are excluded. The total areas of green parks in each scenarios are controlled no more than the given area in the original PUD masterplan.

\subsection{Experimental design}

\subsubsection{Experimental framework}

In the limitation of total green park area, how will various park dispersions impact the urban temperature? Since the study assumes that the dispersion types of park will affect the cooling effect, the dependent variable is the atmospheric temperature and independent variable is park green space distribution type. The study controls variables as Table 2 . The procedure of experimental framework is illustrated as Figure 3.

Table 2. CFD numerical simulation PHOENICS settings

\begin{tabular}{ll}
\hline Parameter & Setting value \\
\hline time & Summer, May, noon \\
Original temperature $\left({ }^{\circ} \mathrm{C}\right)$ & 30.7 \\
Wind speed $(\mathrm{m} / \mathrm{s})$ & 10 \\
Green coverage rate $(\%)$ & 100 (Arbor) \\
\hline
\end{tabular}

\subsubsection{Site}

The research select the PUD 12 of Taichung City as the study site. Its main land use zoning is residential areas with an area of 44.3044 hectares, accounting for $57.61 \%$

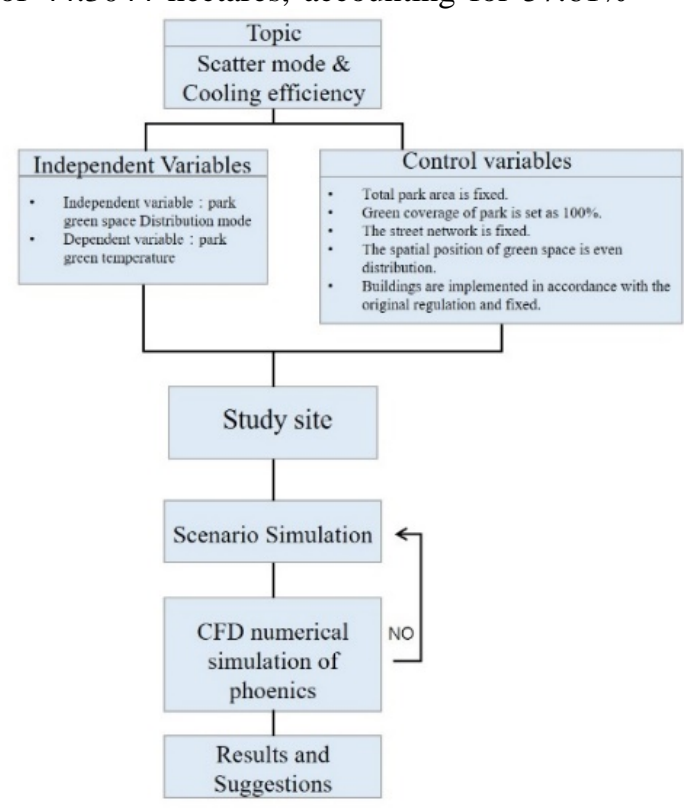

Figure 3. Experimental framework

\subsection{Experimental steps}

This study scattered the central park area by three dispersion types. Each dispersion type is demonstrated as an individual scenario of PUD. The original project of central park with 6 hectares is designated as the control group. Three dispersion types are the 3-hectare type, the 0.5-hectare as district park of the site area. Within the planning area. Public facilities include a central park with area of 6.1528 hectares, accounting for $8 \%$ of the site area, as well as schools, parking areas and square and parking spaces (Fig.4). Even distribution principle.

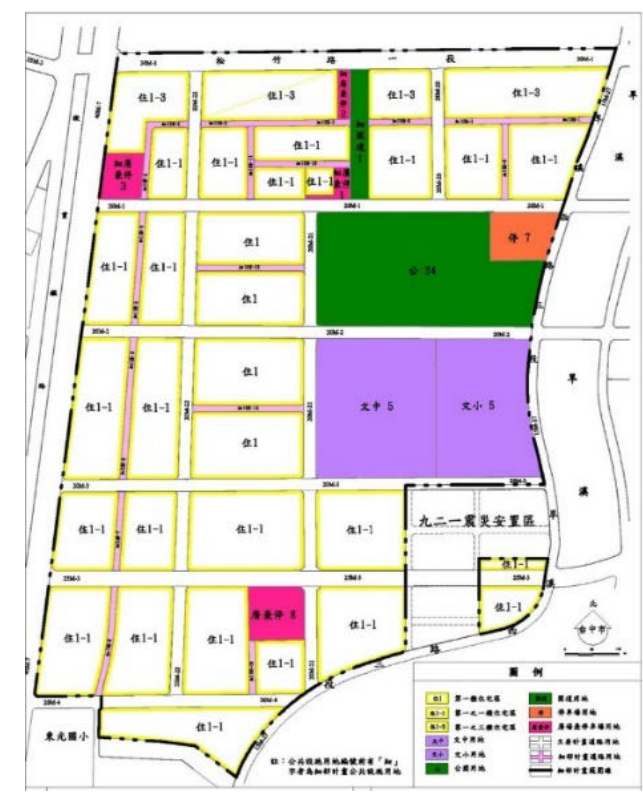

Figure 4. Study site is the PUD 12 of Taichung City

type, neighbourhood park type, and the 0.04-hectare type as pocket park. (Fig.5.) All three types are adapted into the PUD street network and adjust their sizes or amounts to fit in blocks. Each of the three types accounts for a lower ratio than the original central park. According to the PUD guidelines, the buildings is three-floors mass, which is demonstrated as $9 \mathrm{M}$ high. 
- Scenario I (near 3 ha): The whole unit is divided into two sub-areas by the street network. So the 6-hectare central park is dispersed into two parks. Each is located near the center of sub-areas. The total park areas account for $7.08 \%$.

- Scenario II (near 0.5 ha): The whole unit is divided into six sub-areas by the street network. 6-hectare central park is dispersed into 12 pieces of 0.5 -hectare parks. These 12

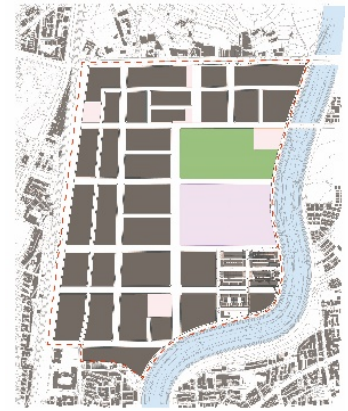

Figure 5.1.

Original plan: 6 ha.

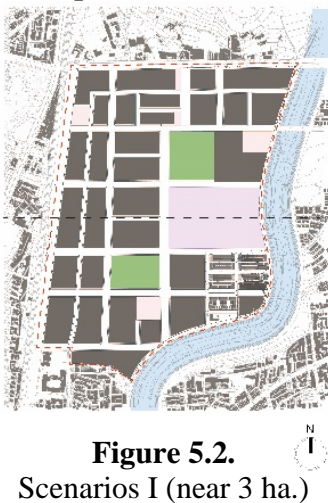

Scenarios I (near 3 ha.)

\section{Results}

In order to discover the temperature patterns in different heights, all four scenarios are simulated in five height, including 5M, 9M, which are among buildings, 10M, 13M, and 16M, which are above buildings. (Fig.6) All the simulations are shown as Fig.8.1 Fig.8.5. The temperature legend is coloured as Fig.7. The results are summarized as follows.

There is a climb-up point of temperature line in each scenario at $10 \mathrm{M}$ height. It is a logical phenomenon because the roofs of buildings would collect heat from sun and radiate the heat, which causes the temperature rise. However, on analysis of temperature pattern, the Scenario III(0.04 ha) always has the most cooler area(shown as light blue to deep blue), and the secondary is Scenario II(near 0.5 ha), the third

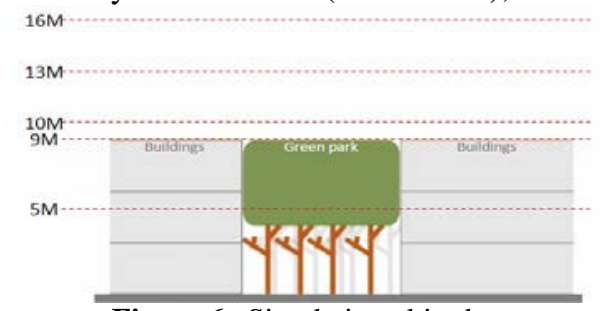

Figure 6. Simulation altitudes

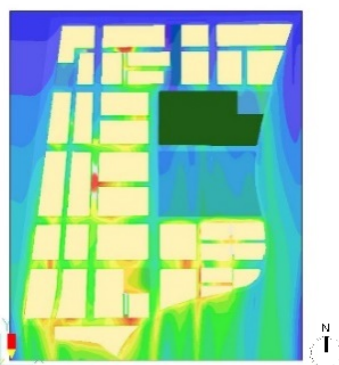

Figure 8.1.1. Hight_5M Original plan: 6 ha.

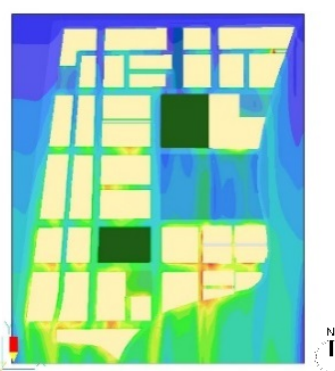

Figure 8.1.2. Hight_5M Scenario I: 3 ha pieces are distributed averagely into six sub-areas. The total park areas account for $7.12 \%$.

- Scenario III(0.04 ha): 6-hectare central park is dispersed into 140 pieces of 0.04 -hectare parks. These 140 pieces are distributed averagely around the whole site. The total park areas account for $7.43 \%$.
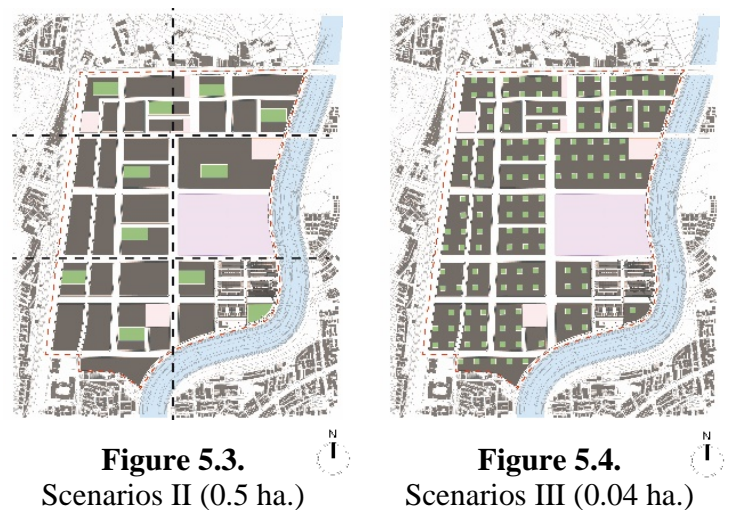

is Scenario I (near $3 \mathrm{ha}$ ), and the original plan has the fewest cooler area. Similarly, on analysis of average temperature (Fig.9), the line of Scenario III (0.04 ha) always runs at the lowest, which means the coolest. The bottom-up sequences of other lines are Scenario II, Scenario I, and the original plan. The results reveal that the more dispersed the park, the lower the average temperature, which means a better cooling effect. Furthermore, the differences of temperature between scenarios are bigger in the height from $9 \mathrm{M}$ to $13 \mathrm{M}$, and tend to convert at higher altitude. It reveals that the difference of cooling impact is limited in an extent, which is from the top above of the trees to about seven meters higher. All these conclusions are suggested to the climate responsive urban planning and design.

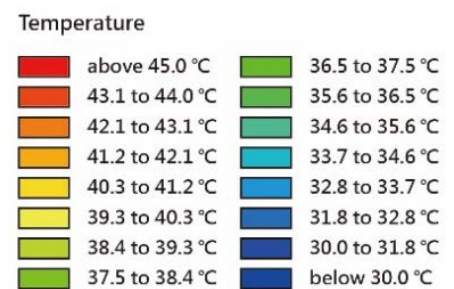

Figure 7. Temperature legend

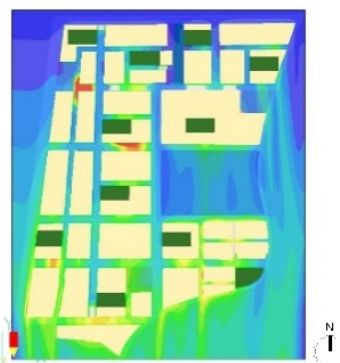

Figure 8.1.3. Hight_5M Scenario II: 0.5 ha

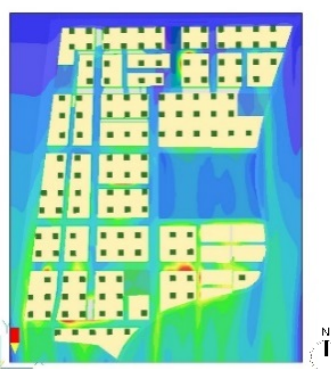

Figure 8.1.4. Hight_5M Scenario III: 0.04 ha 


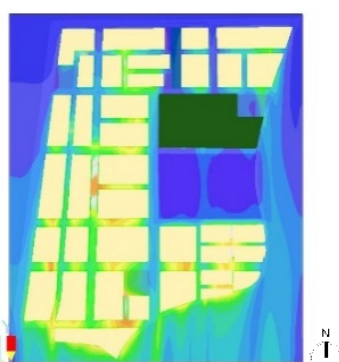

Figure 8.2.1 Hight_9M Original plan: 6 ha.

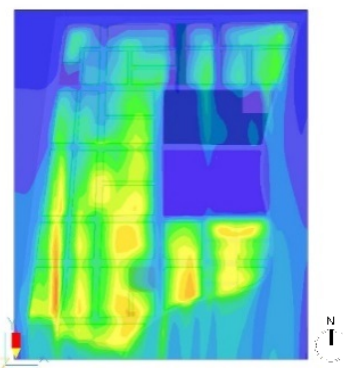

Figure 8.3.1 Hight_10M Original plan: 6 ha.

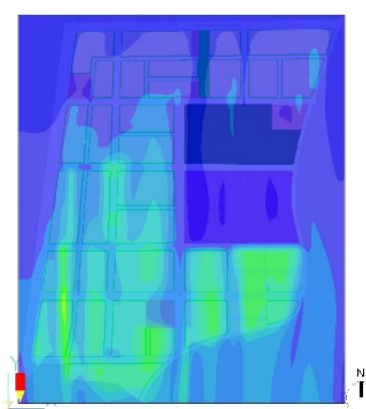

Figure 8.4.1 Hight_13M Original plan: 6 ha.

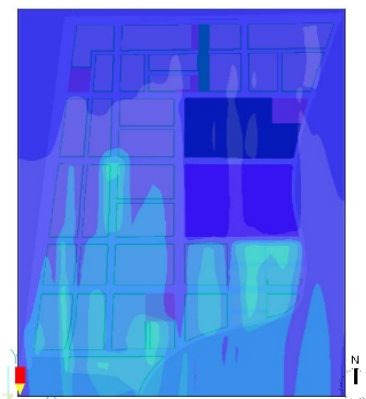

Figure 8.5.1 Hight_16M Original plan: 6 ha.

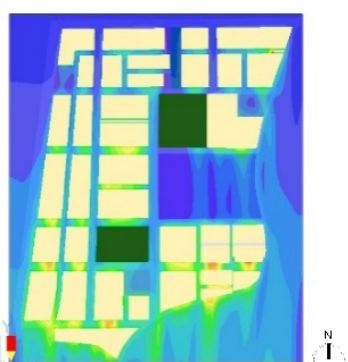

Figure 8.2.2 Hight_9M Scenario I: 3 ha

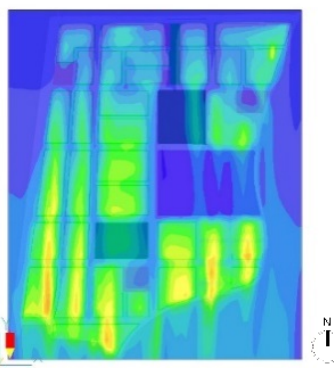

Figure 8.3.2 Hight_10M Scenario I: 3 ha

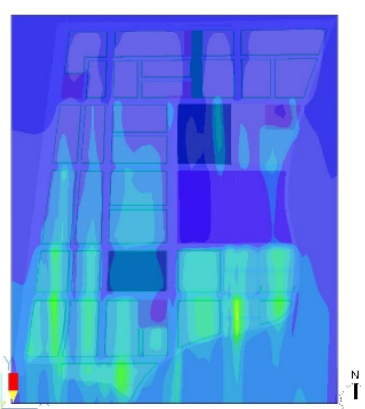

Figure 8.4.2 Hight_13M Scenario I: 3 ha

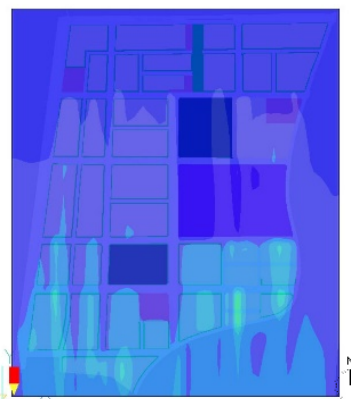

Figure 8.5.2 Hight_16M Scenario I: 3 ha

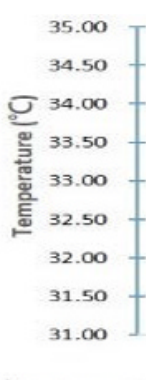

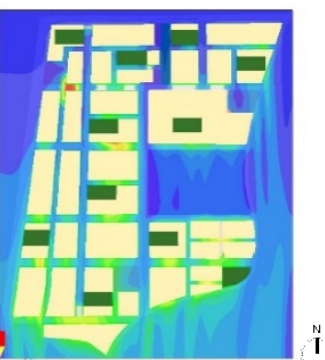

Figure 8.2.3 Hight_9M Scenario II: 0.5 ha

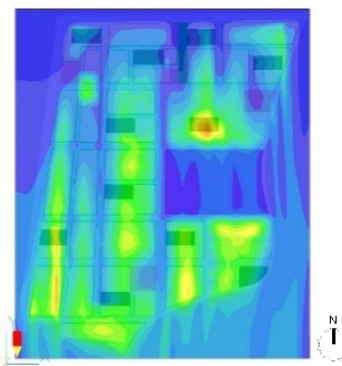

Figure 8.3.3 Hight_10M Scenario II: 0.5 ha

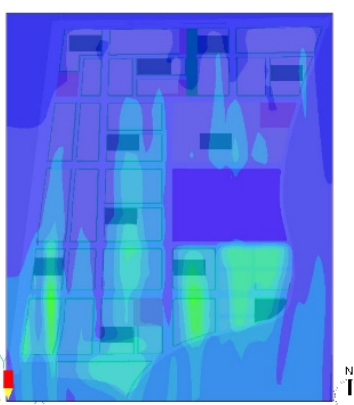

Figure 8.4.3 Hight_13M Scenario II: 0.5 ha

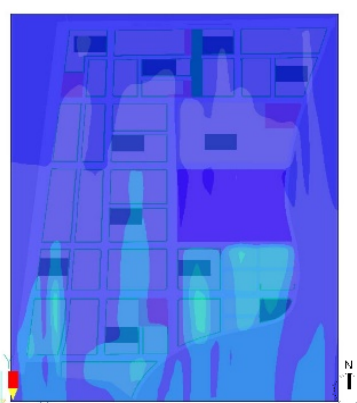

Figure 8.5.3 Hight_16M Scenario II: 0.5 ha

- $-6 \mathrm{HA}$

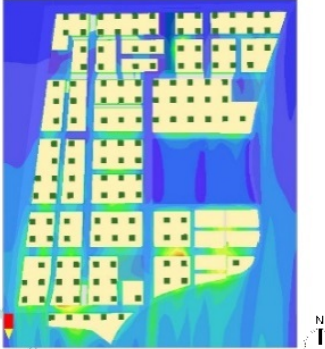

Figure 8.2.4 Hight_9M Scenario III: 0.04 ha

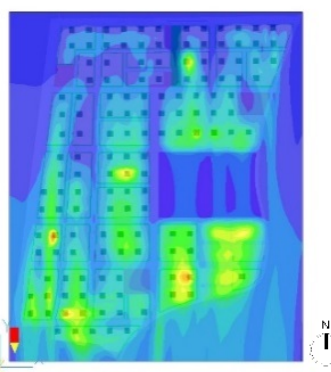

Figure 8.3.4 Hight_10M Scenario III: 0.04 ha

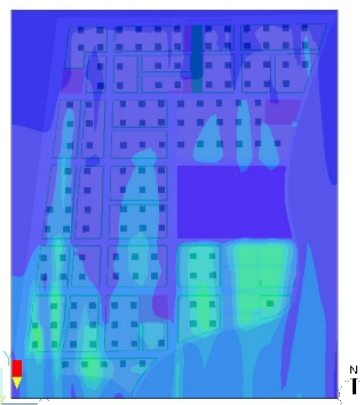

Figure 8.4.4 Hight_13M Scenario III: 0.04 ha

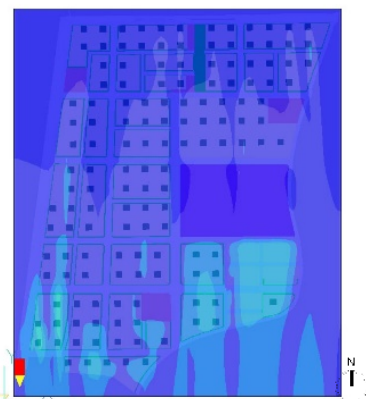

Figure 8.5.4 Hight_16M Scenario III: 0.04 ha

Average

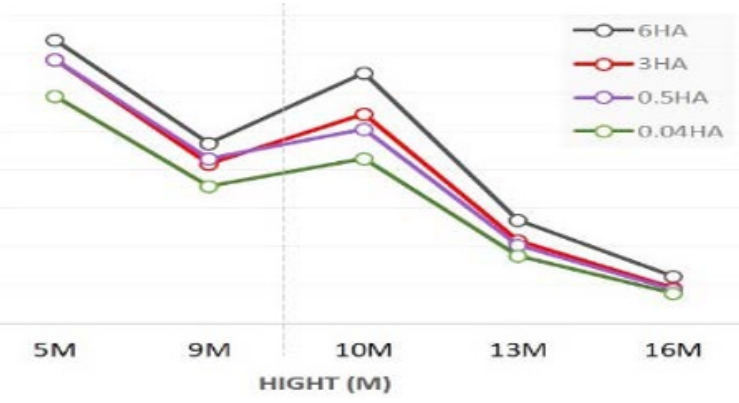

Figure 9. The Average temperature of 5 heights of 4 scenarios 


\section{References}

1. C. T. Lin, 2016, Urban Forestry \& Urban Greening Volume 20, Preliminary study of the influence of the spatial arrangement of urban parks on local temperature reduction, pp.348-357

2. M. H. Lee, 2004, A Study on the Relationship between Urban Parks and Local-climate - A Case Study in Taipei.

3. Wenqi Lin, Ting Yu, Xiangqi Chang, Weijia Wu, Yue Zhang, 2015, Calculating cooling extents of green parks using remote sensing: Method and test, Landscape and Urban Planning 134 (2015) 66-75

4. Construction and Planning Agency (CPAMI), 2011, Planning and Design Handbook of Park Greenbelt system.

5. Masatoshi Yoshino, 1976, 《Microclimate》, Daming Church Co., Ltd.

6. Boundary Layer Climate (Second Edition). By T. R. Oke. May Hugh. year 1987. 